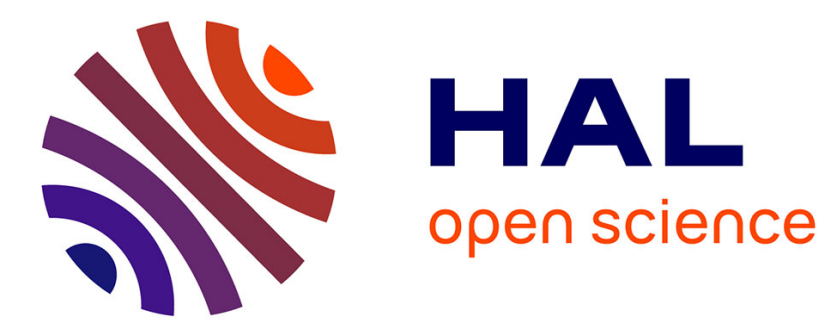

\title{
Chaos time-domain reflectometry for distributed diagnosis of complex topology wired networks
}

F. Auzanneau

\section{To cite this version:}

F. Auzanneau. Chaos time-domain reflectometry for distributed diagnosis of complex topology wired networks. Electronics Letters, 2016, 52 (4), pp.280-281. 10.1049/el.2015.3456 . cea-01755115

\section{HAL Id: cea-01755115 https://hal-cea.archives-ouvertes.fr/cea-01755115}

Submitted on 10 Jan 2019

HAL is a multi-disciplinary open access archive for the deposit and dissemination of scientific research documents, whether they are published or not. The documents may come from teaching and research institutions in France or abroad, or from public or private research centers.
L'archive ouverte pluridisciplinaire HAL, est destinée au dépôt et à la diffusion de documents scientifiques de niveau recherche, publiés ou non, émanant des établissements d'enseignement et de recherche français ou étrangers, des laboratoires publics ou privés. 


\section{Chaos time-domain reflectometry for distributed diagnosis of complex topology wired networks}

\section{F. Auzanneau}

A new reflectometry-based wire diagnosis method using chaotic signals is presented. It shows excellent potential for the diagnosis of live wires (i.e. during their operational usage) and complex topology networks. The use of chaotic signals for distributed diagnosis and the detection of defects in wires is investigated. Chaos time-domain Reflectometry (CTDR) using low auto-correlation sidelobes signals, shows high performances in very noisy environment: the detection and location of hard defects are possible, even if several reflectometers inject their signals concurrently with the diagnosis and the normal operation of the cable. This enables using CTDR for distributed diagnosis of complex topology networks.

Introduction: In many application domains, wire faults can have dramatic consequences. Live wire diagnosis is often required to ensure permanent monitoring of the health of embedded cables. Reflectometry methods are among the most commonly used methods for this purpose [1]. Similarly to Radar, reflectometry injects a probe signal at one end of the network under test. This signal propagates along the cables and each impedance discontinuity met (junction or defect) sends a part of its energy back to the injection port. The analysis of the measured signal provides information on the presence, the location and the type of these discontinuities.
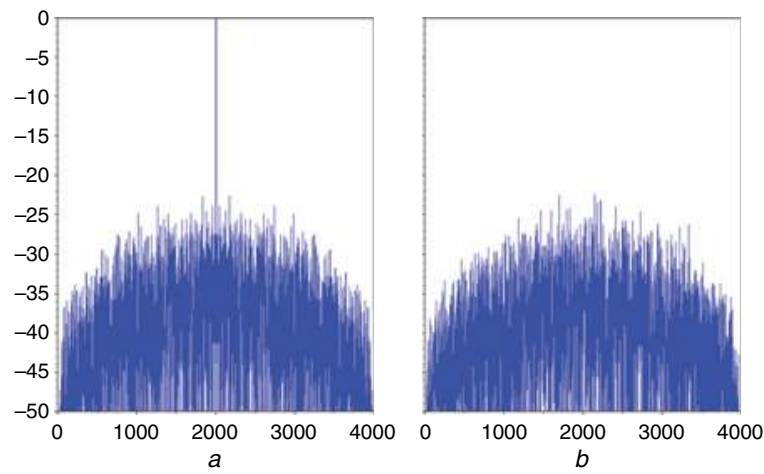

Fig. 1

a Auto-correlation

$b$ Cross-correlation of two chaotic signals, using $N=10, M=200, k_{1}=3.9$ and $k_{2}=3.900001$, and random initial conditions $x_{0}$

Smart energy grids are more and more used for the intelligent distribution of energy generated by several inhomogeneous sources, such as wind farms, solar power plants, nuclear and fuel power plants. They also provide additional services, such as integrated communication, sensing and measurement, to improve reliability and flexibility. In this context, the electric network structure is often complex, comprising several split points and multiple branches. Standard reflectometry methods are not suited for monitoring and diagnosis of this kind of networks, because the injected signal bounces at the junctions and creates multiple copies of itself, which propagate several times in all the cables before coming back to the injection point. The measured reflectogram is very complex and can provide ambiguous location for the defects. Ravot et al. in [2] have proposed distributed reflectometry where several reflectometers are used simultaneously to improve the diagnosis result. This requires that the signals from each sensor do not interfere with the other distributed sensors, in order to prevent any false alarm.

Chaos theory describes systems whose behaviour is highly dependent on initial conditions, and becomes very difficult to predict in time. Chaos theory has grown and been applied in many domains, from astrophysics to economics, computer science, aerodynamics, chemistry and biology. Attractors and bifurcation diagrams, among others, help show the sensitive dependence of the evolution of a chaotic system on initial conditions. Recent works have also shown its very promising potential for high precision detection and location of defects in wires [3-5], leading to the new chaos time-domain reflectometry (CTDR) method.
In this Letter, chaotic signals show very good auto-correlation and cross-correlation characteristics and the capacity of generating virtually an infinite number of orthogonal signals. This feature is exploited for the distributed diagnosis of complex topology networks.

Chaos time-domain reflectometry: In CTDR, chaotic signals are generated by logistic and Bernoulli maps [6]. The logistic map (1), with an initial parameter set $\left\{x_{0}, k\right\}$, is used to generate the parameters of the Bernoulli map (2)

$$
\begin{gathered}
x_{m}=k x_{m-1}\left(1-x_{m-1}\right) \\
y_{m, n+1}=\left\{\begin{array}{ll}
B_{m} y_{m, n}+0.5 & \text { if } y_{m, n}<0 \\
B_{m} y_{m, n}-0.5 & \text { if } y_{m, n} \geq 0
\end{array} \quad n=1, \ldots, N\right.
\end{gathered}
$$

with

$$
B_{m}=1.4+0.6 x_{m}
$$

Then, $M$ sets of data $Y_{m}=\left[y_{m, 1}, y_{m, 2} \ldots y_{m, N}\right]^{t}, m=1, \ldots, M$, where the superscript $t$ stands for the transpose, are gathered to create the chaotic signal $S_{\mathrm{c}}=\left[Y_{1} Y_{2} \ldots Y_{M}\right]^{\mathrm{t}}$. The signal $S_{\mathrm{c}}$ is fully described by its parameter set $\left\{x_{0}, k, N, M\right\}$.

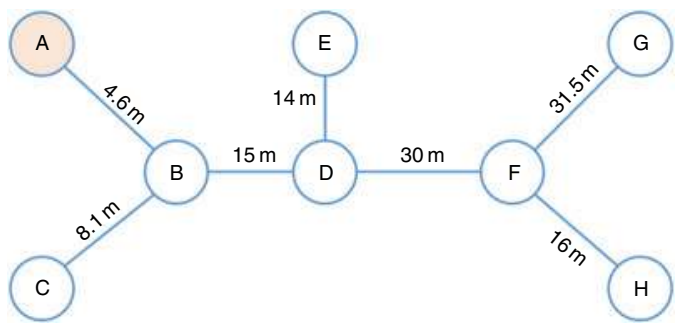

Fig. 2 Complex network topology

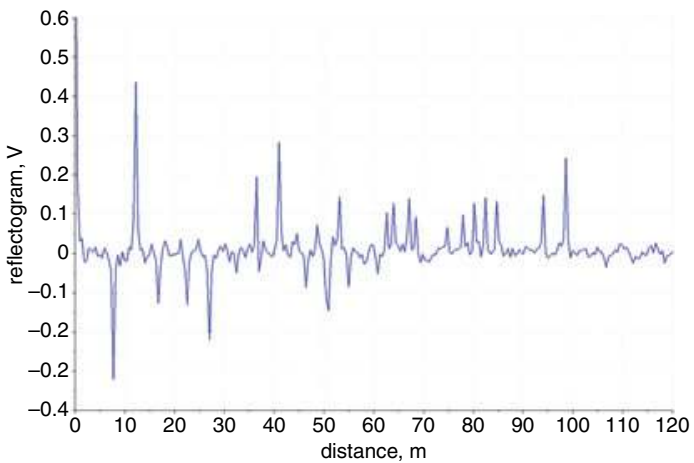

Fig. 3 Reflectogram from point A. CTDR signal's parameters: $N=50$, $M=200, k=3.9$

Fig. 1 shows the auto-correlation and cross-correlation levels of two chaotic signals [plots in decibel using $20 \log _{10}($.$) ] generated using$ $N=10, M=200$ and very close $k$ values. The secondary lobes and crosscorrelation levels are close to $-22 \mathrm{~dB}$, even for such a small difference in the $k$ parameters. Simulations have shown that increasing the length of the signals reduces the secondary lobes and cross-correlation levels. They can be roughly approximated by the following formula:

$$
\max _{\text {lobes }} \simeq-7 \log _{10}(N M)
$$

Complex network diagnosis: A simple model is used to compute the reflectogram of a network, given its topology and the reflectometry probe signal. The signal measured by the sensor is made of several delayed copies of the injected signal. Then the reflectogram is computed by the cross-correlation of the measured signal $S$ with the injected signal $S_{\mathrm{c}}$

$$
R(t)=S(t) \otimes S_{\mathrm{c}}(t)
$$

Knowing the propagation speed in the cables enables to plot $R$ as a function of the distance in the network from the injection point. The peaks on the reflectogram plot show the impedance discontinuities, either junctions, loads at cables ends or defects. 
An example of complex topology has been taken from [7], as shown in Fig. 2. Fig. 3 plots the reflectogram when the sensor is placed at point A: although the topology does not seem very complex, the plot shows a high number of peaks, some of them further away than the largest distance in the network (from A to G: $81.1 \mathrm{~m}$ ). The measured noise level is close to $-30 \mathrm{~dB}$, according to formula (4).

Online distributed diagnosis: In such a complex reflectogram, it is not easy to precisely locate a defect in the branches of the network: a single sensor at point A cannot tell a defect from branches $\mathrm{F}-\mathrm{G}$ to $\mathrm{F}-\mathrm{H}$ or from branches D-E to D-F. To provide unambiguous defect location, one must add other sensors at other ends of the network [2]. Such a distributed diagnosis enables to compare various reflectograms to locate more precisely the defects and cancel ambiguities. However, to prevent a signal from one sensor from triggering a false alarm in another sensor, the signals from all the reflectometers must have crosscorrelation levels lower than or similar to the noise level $n$ :

$$
\max _{i \neq j \in\{\text { sensors }\}}\left(S_{\mathrm{c}, i}(t) \otimes S_{\mathrm{c}, j}(t)\right) \leq n(t)
$$

As shown in Fig. $1 b$ and formula (4), CTDR naturally achieves this aim. Fig. 4 plots the reflectogram from point $A$ with four additional sensors at points $\mathrm{C}, \mathrm{E}, \mathrm{G}$ and $\mathrm{H}$ with $N=5, M=200$ and random initial parameter sets $\left\{x_{0}, k\right\}$. The comparison with Fig. 3 shows similar peaks positions and amplitudes. The measured noise level on the reflectogram has increased to $-28 \mathrm{~dB}$.

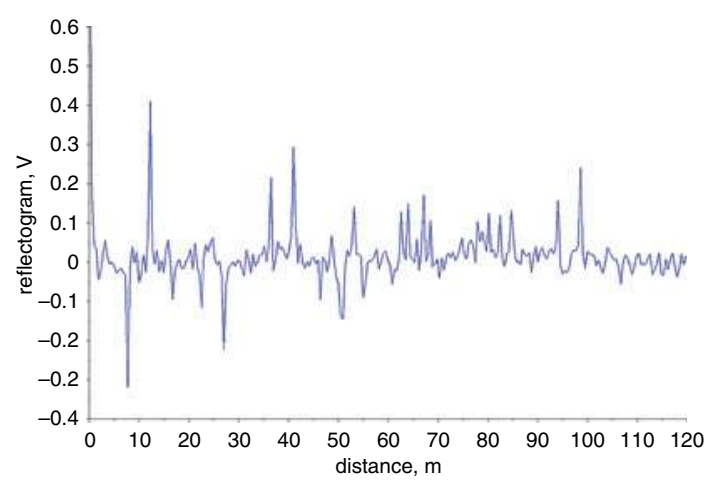

Fig. 4 Reflectogram from point $A$, with four emitting sensors at points $C, E$, $G$ and H. CTDR signal's parameters: $N=50, \quad M=200, k=3.9+$ rand $(0,1) / 100$

A more complex case has been simulated in Fig. 5 with 10 (red curves) and 20 (blue curves) additional sensors emitting concurrently with sensor A. The reflectogram from sensor A remains processable although the noise level has increased to $-24 \mathrm{~dB}$ for 10 sensors and close to $-20 \mathrm{~dB}$ for 20 sensors.

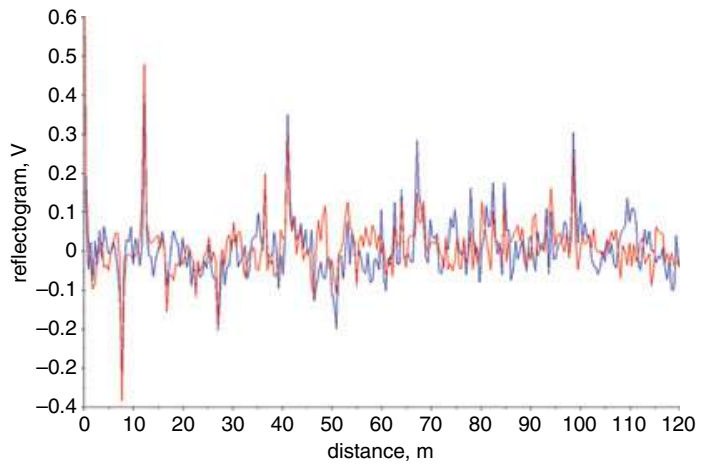

Fig. 5 Reflectogram from point A, with 10 (red curves) and 20 (blue curves) random emitting sensors
Additional simulations (not shown here), with $N=50$ and $M=2000$, present noise levels of $-35 \mathrm{~dB}$ for a single sensor, around $-32 \mathrm{~dB}$ with 4 additional sensors and $-28 \mathrm{~dB}$ for 20 concurrent sensors. Multiplying $M$ by 10 brought an $8 \mathrm{~dB}$ decrease of the noise level.

Conclusion: The efficiency of CTDR for the distributed diagnosis of complex topology wired networks has been shown. CTDR's capacity of generating a quasi-infinite number of low auto-correlation sidelobes and low cross-correlation signals enables several reflectometers to simultaneously inject their signals in the cables, without any interference. Very complex topologies, with a high number of branches, can be addressed, as it is shown that adding 20 concurrent sensors still enables to process the reflectograms. Increasing the length of the chaotic signal enables to decrease the noise level.

Future work will investigate CTDR's very high noise resistance and noise management, applied to the diagnosis of soft defects in cables.

(C) The Institution of Engineering and Technology 2016

Submitted: 2 November 2015

doi: $10.1049 / \mathrm{el} .2015 .3456$

One or more of the Figures in this Letter are available in colour online.

F. Auzanneau (CEA, LIST, F-91191 Gif-sur-Yvette, France)

$\bowtie$ E-mail: fabrice.auzanneau@cea.fr

\section{References}

1 Auzanneau, F.: 'Wire troubleshooting and diagnosis: review and perspectives', Prog. Electromagn. Res. B, 2013, 49, pp. 253-279, doi: 10.2528/ PIERB1302011

2 Ravot, N., and Olivas Carrion, M.: 'Distributed reflectometry-based diagnosis for complex wired networks'. EMC Europe Workshop, Paris, France, June 2007

$3 \mathrm{Xu}, \mathrm{H}$., Wang, B., and Wang, A.: 'Location of wire faults using chaotic signal generated by an improved Colpitts oscillator', Int. J. Bifurcation Chaos, 2014, 24, p. 1450053, doi: 10.1142/S0218127414500539

4 Zhang, J.G., Xu, H., and Wang, B.: 'Wiring fault detection with Boolean-chaos time-domain reflectometry', Nonlinear Dyn., 2015, 80, pp. 553-559, doi 10.1007/s11071-014-1888-x

$5 \mathrm{Xu}, \mathrm{H} ., \mathrm{Li}, \mathrm{J}$., and Wang, B.: 'Chaos time domain reflectometry for fault location on live wires', J. Appl. Anal. Comput., 2015, 5, pp. 243-250, doi: 10.11948/2015022

6 Yang, Q., and Zhang, Y.: 'A signal model based on combination chaotic map for noise radar', Progr. Electromagn. Res. M, 2013, 28, pp. 57-71, doi: 10.2528/PIERM12111707

7 Ulrich, M., and Yang, B.: 'Inference of wired network topology using multipoint reflectometry'. Proc. of 23rd European Signal Processing Conf. - EUSIPCO, Nice, France, August 2015 